\title{
A Minimal Access Zygomatic Osteotomy Technique for the Correction of Facial Deformity
}

\author{
Alice R Hamilton, BDS, BSc(Hons) MFDS*, Luke Bowen, BDS, Jaime Grant, MBChB, FRCSEd and Duncan \\ F Campbell, FRCS(OMFS) FRCS, FDS, MB, BS, BDS
}

Department of Oral and Maxillofacial Surgery, St John's Hospital, Livingston, Scotland

\begin{abstract}
Zygomatic osteotomies for correction of late presentation zygomatic complex fractures or hypoplasia resulting in facial deformity has traditionally required access to the zygomatic complex via a coronal approach. Coronal access can be time consuming and carries a relatively high morbidity rate, leaving a large scar that can be obvious when the hair is short, absent or wet. This paper discusses the modification of a minimal access zygomatic osteotomy, which we previously described for the correction of zygomatic orbital hypoplasia, The Edinburgh technique. The technique was adapted using saw blades instead of diamond wires for the reduction of the malunion of a late presentation post-traumatic zygomatic complex fracture. The procedure was performed in conjunction with 3D planning resulting in a successful outcome, reduced morbidity and reduced operating time.
\end{abstract}

\section{Keywords}

Minimal access, Zygomatic, Osteotomy, Trauma, Facial deformity, Edinburgh technique

\section{Introduction}

Zygomatic osteotomies for the malunion of the displaced zygomatic complex fracture due to late presentation have traditionally required access to the zygoma via a coronal approach. This approach can be a time consuming with relatively high morbidity, often leaving a large scar which can be obvious when the hair is short, absent or wet [1-3]. Here we discuss an alternative approach using the adaptation of a minimal access technique [4] in conjunction with 3D planning to facilitate post-traumatic zygomatic osteotomy with a successful outcome, reduced morbidity and reduced operating time.

\section{Case}

A 39-year-old male was referred to the Oral and Maxillofacial Department for management of a right zygomatic complex fracture which had been sustained in an alleged assault three months previously. He presented with a malunion of the right zygoma leading to loss of prominence of the right cheek and right infraorbital nerve parasthesia. The patient consented to have a minimal access zygomatic osteotomy under general anaesthetic to correct the facial deformity.

\section{D Planning}

The DICOM data from a head CT was transferred to 3D slicer software. 3D models were then segmented as shown in (Figure 1). Computer planning was performed manually by the operating surgeon thus negating the need for external providers and cutting costs to the unit.
The 3D planning models allow the surgeon to plan surgical cuts and movements required pre-operatively therefore facilitating a more accurate, planned approach, with reduced surgical time.

\section{Surgical steps}

Access:

- Upper blepharoplasty incision

- Transconjunctival incision

- Intra-oral vestibular sulcal incision

- Combined with sub-periosteal dissection to provide access to:

- $\quad$ Frontozygomatic (FZ) suture

- Extra orbital posterior aspect of the frontal process of the zygoma

*Corresponding author: Alice R Hamilton, BDS, BSc(Hons) MFDS, Department of Oral and Maxillofacial Surgery, St John's Hospital, Livingston, EH54 6PP, Scotland

Accepted: September 14, 2020

Published online: September 16, 2020

Citation: Hamilton AR, Bowen L, Grant J, et al. (2020) A Minimal Access Zygomatic Osteotomy Technique for the Correction of Facial Deformity. Archives Oral Maxillofac Surg 3(1):59-5861 


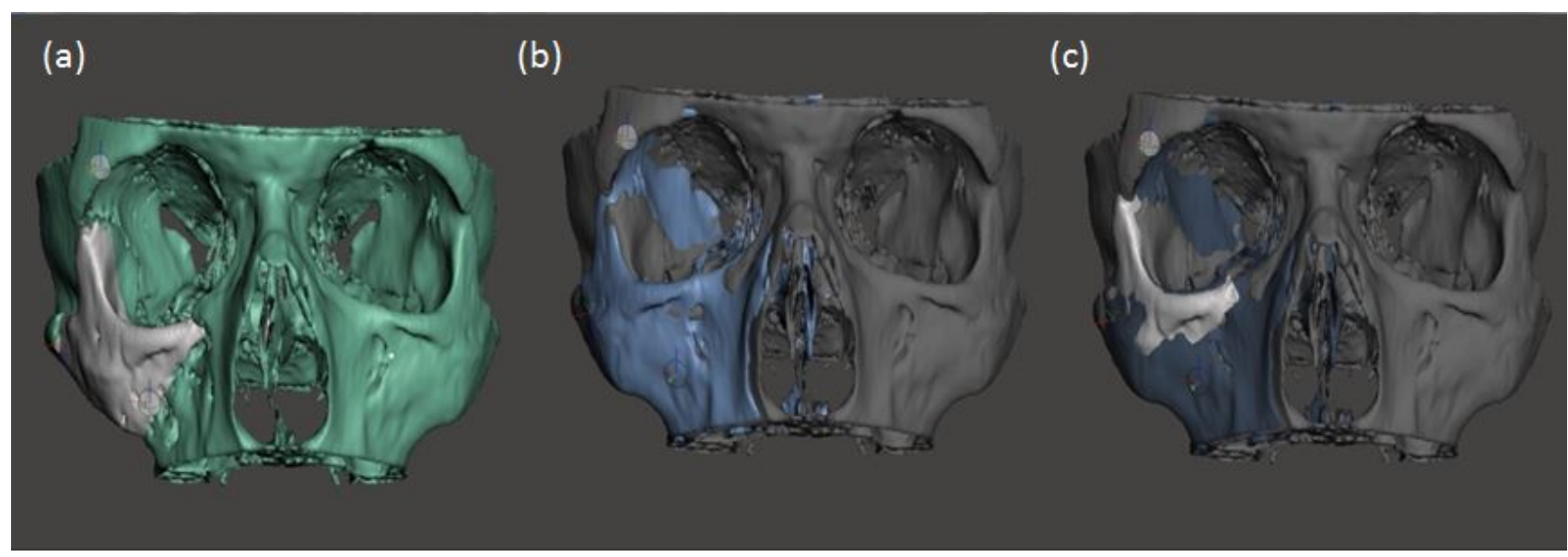

Figure 1: 3D planning models showing: (a) Right zygomatic fracture without adjustment; (b) Right zygomatic fracture with overlaying mirror of right zygoma; (c) Adjustment of mirrored right zygoma maximising fit with ideal symmetry.

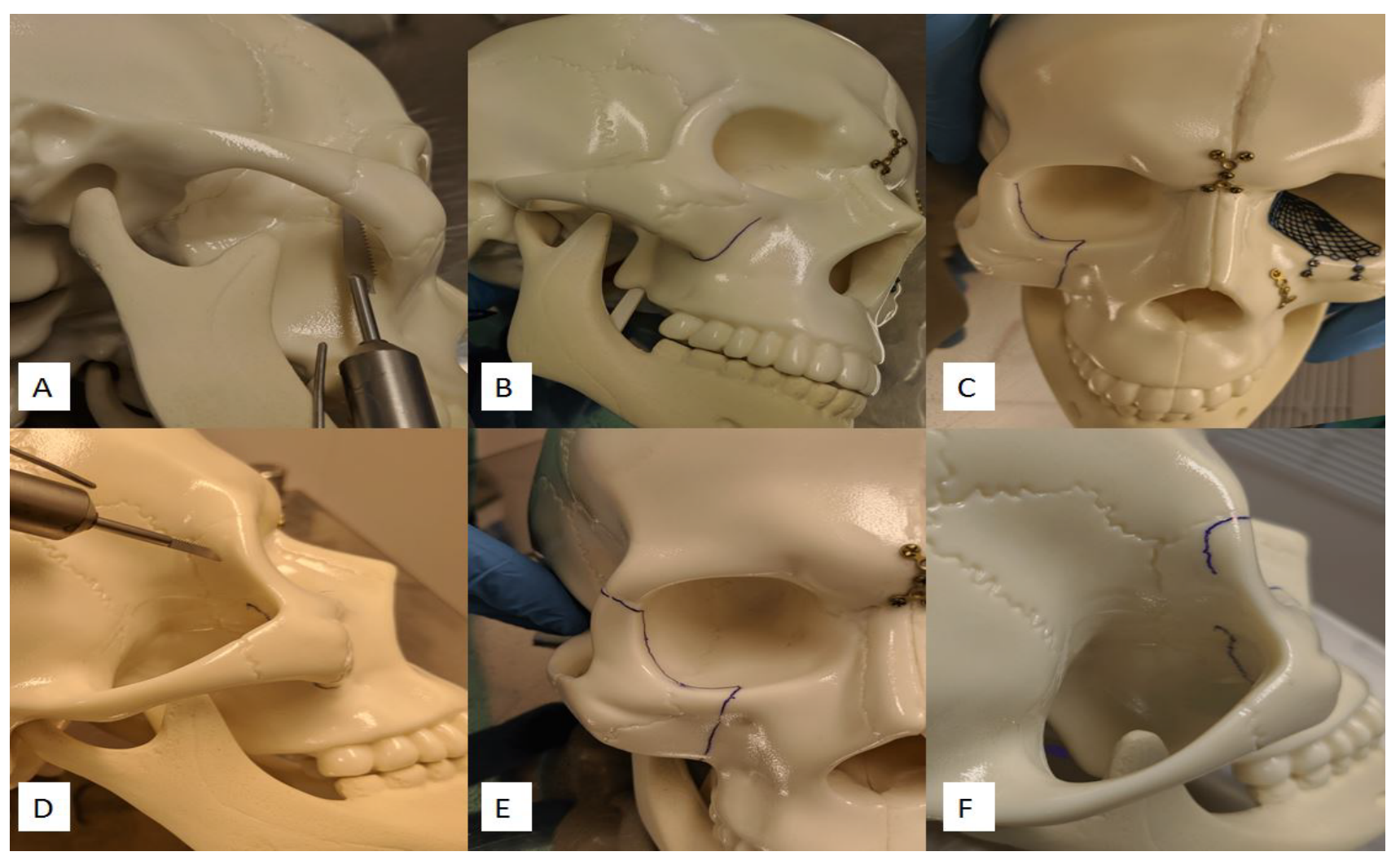

Figure 2: Photographs A to F showing path of surgical cuts.

- Floor and lateral wall of the orbit

- Anterior maxilla

- Body and arch of zygoma

\section{Surgical cuts}

Via the sulcus incision: A reciprocating saw was used to cut the junction of the frontal process of the zygoma/sphenoid for $35 \mathrm{~mm}$ (full length of blade) continuing the cut through the buttress and extending onto the anterior maxilla towards the lateral aspect of the infraorbital foramen (Figure $2 \mathrm{~A}$ and Figure 2B).
Via the transconjunctival incision: A micro saw was used to cut through the infra orbital rim immediately lateral to the infraorbital foramen, protecting the nerve and linking to the anterior maxillary cut. Then at right angles cut laterally, parallel to but $5 \mathrm{~mm}$ posterior to the orbital rim extending superolateral to just below the lateral canthus (Figure 2C).

Via the upper blepharoplasty incision: Whilst protecting the eye, a cut was made at a right angle, horizontally across the posterosuperior surface of the lateral orbital wall, at approximately $3 \mathrm{~mm}$ below the ZF suture (Figure 2D), joining with the previous cut (Figure 2E). 


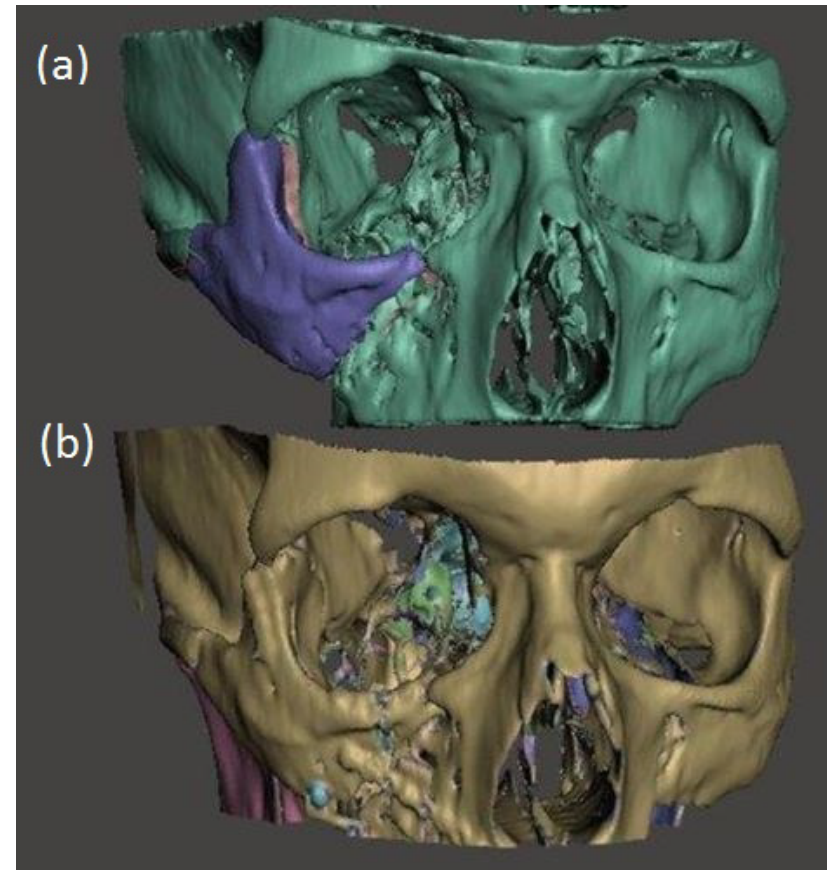

Figure 3: (a) 3D model showing mirror of the right zygoma with adjustments to achieve ideal symmetry; (b) Post-operative CT scan converted into 3D software, showing achieved post operative result.

Due to limited access to the infra-temporal space there was a small area there the cuts could not be joined (Figure $2 \mathrm{~F})$. Gentle elevation of the zygomatic complex at the buttress lead to propagation of the cuts through this area. Final reduction to the planned projection was achieved through flexion or 'greenstick' of the zygomatic arch. Fixation was carried out with a plate at the FZ suture, the inferior orbital rim and two plates at the anterior zygomatic buttress. Incisions were closed by standard technique. The post-operative CT scan was compared with the mirror of the right zygoma with ideal symmetry demonstrating an excellent result (Figure 3).

\section{Discussion}

Philip and Campbell, et al. [4] discussed a minimal access technique; The Edinburgh technique for the correction of zygomatic orbital hypoplasia to try circumvent the potential morbidities encountered through bicoronal access. Here we have adjusted that technique with the use of saw blades as opposed to diamond wires to achieve a satisfactory outcome for a post-traumatic zygomatic osteotomy avoiding the need for a coronal flap.

On comparing the planning image of the mirrored right zygoma which was adjusted to achieve ideal symmetry, with the CT scan of the final surgical outcome, it shows that excellent bony contour and projection has been achieved (Figure 3).

As this is our second use of this technique it will require further investigation to ensure safety and reproducibility of results. When carrying out this technique, the first cut, at the infratemporal surface should be bold with a long saw blade due to limitations in infratemporal access. At this early stage, the modified technique has been able to show promising surgical outcomes, with reduced operating time, reduced surgical morbidity and excellent patient satisfaction.

\section{Conflict of Interest}

No conflict of interest.

\section{Funding}

None.

\section{References}

1. Gabrielli MA, Monnazzi MS, Gabrielli MF, et al. (2012) Clinical evaluation of the bicoronal flap in the treatment of facial fractures. Retrospective study of 132 patients. J Cranio Maxill Surg 40: 51-54.

2. Zhang Q, Dong J, Li Z, et al. (2006) Coronal incision for treating zygomatic complex fractures. J Cranio Maxill Surg 34: 182-185.

3. Abubaker AO, Sotereanos G, Patterson GT, et al. (1990) Use of the coronal surgical incision for reconstruction of severe craniofacial injuries. J Oral Maxillofac Surg 48: 579-586.

4. Philip JN, Campbell DF (2017) The Edinburgh modification of the minimal access zygomatic osteotomy used for the correction of zygomatic orbital hypoplasia. Int J Oral Maxillofac Surg 46: 11021105.

DOI: $10.36959 / 379 / 355$ 